\title{
On the Existence of Hydrotalcite-Like Phases in the Absence of Trivalent Cations
}

\author{
P. Vishnu Kamath ${ }^{1}$ and G. Helen Annal Therese \\ Department of Chemistry, Central College, Bangalore University, Bangalore 560001, India \\ and \\ J. Gopalakrishnan ${ }^{1}$ \\ Solid State and Structural Chemistry Unit, Indian Institute of Science, Bangalore 560012, India
}

Received February 19, 1996; in revised form August 6, 1996; accepted September 10, 1996

\begin{abstract}
$\alpha$-Hydroxides of nickel(II) and cobalt(II) are hydrotalcite-like phases, possessing a layered double hydroxide (LDH) structure even though there are no trivalent cations in the lattice. While the LDHs acquire a positive charge on the hydroxide layers by the incorporation of trivalent cations, we suggest that the $\alpha$-hydroxides acquire a positive charge by partial protonation of the hydroxyl ions according to the equation
\end{abstract}

$$
M(\mathrm{OH})_{2}+x \mathrm{H}^{+} \rightarrow\left[M(\mathrm{OH})_{2-x}\left(\mathrm{H}_{2} \mathrm{O}\right)_{x}\right]^{x+} .
$$

As in the LDHs, charge balance is restored by the incorporation of anions in the interlayer region. (C) 1997 Academic Press

\section{INTRODUCTION}

The mineral hydrotalcite (HT) $\mathrm{Mg}_{6} \mathrm{Al}_{2}(\mathrm{OH})_{16} \mathrm{CO}_{3}$. $4 \mathrm{H}_{2} \mathrm{O}$ together with other isotypic minerals, such as pyroaurite (1), reevesite (2), takovite (3), honessite (4), desaultesite (5), motukoreaite (6), and iowite (7), belong to a general family of compounds known as layered double hydroxides (LDHs) (8). Also belonging to this family are the hydrocalumite $\mathrm{Ca}_{2} \mathrm{Al}(\mathrm{OH})_{6} \mathrm{NO}_{3} \cdot 3 \mathrm{H}_{2} \mathrm{O}$ and its $\mathrm{Zn}$ analog (9). All the LDHs can be generally formulated as $M_{1-x}^{\mathrm{II}} M^{\prime \prime I I I}(\mathrm{OH})_{2} A_{x / n}^{n-} \cdot m \mathrm{H}_{2} \mathrm{O}$, where $M=\mathrm{Mg}, \mathrm{Co}, \mathrm{Ni}$; $M^{\prime}=\mathrm{Al}, \mathrm{Cr}, \mathrm{Mn}, \mathrm{Fe}$; and $A=\mathrm{NO}_{3}^{-}, \mathrm{ClO}_{4}^{-}, \mathrm{BrO}_{3}^{-}, \mathrm{OH}^{-}$, $\mathrm{CO}_{3}^{2-}, \mathrm{SO}_{4}^{2-}$. For most LDHs, $x=0.25$, except for $M=\mathrm{Ca}, \mathrm{Zn}$ where $x=0.33$. The various minerals referred to above differ from each other in the identity of the metals $M$ and $M^{\prime}$, or the $A$ anions involved. In view of the possible application of LDHs as catalysts (10), anion exchangers (11), precursors to oxides (12), and electrodes for alkaline second-

\footnotetext{
${ }^{1}$ To whom correspondence should be addressed.
}

ary cells (13), there has been considerable interest in the synthesis of these minerals by chemical routes that involve precipitation (14), hydrothermal (15), or electrochemical reactions (16).

The basic building unit of all the LDHs is the brucite, $\mathrm{Mg}(\mathrm{OH})_{2}$, structure. $\mathrm{Mg}(\mathrm{OH})_{2}$ crystallizes in a layered hexagonal structure $(P \overline{3} m 1 a=3.147 \AA, c=4.769 \AA)$ consisting of a close packed array of hydroxyl ions, where the $\mathrm{Mg}^{\mathrm{II}}$ ions occupy alternate layers of octahedral sites. Accordingly, the structure is built-up of charge-neutral $\mathrm{Mg}(\mathrm{OH})_{2}$ layers which are stacked one over the other along the $c$ direction. The interlayer region in the structure, where the hydroxyl protons reside, is essentially empty. The $\mathrm{LDH}$ structure is derived from the brucite structure by replacing a certain fraction, $x$, of divalent $\mathrm{Mg}^{\mathrm{II}}$ by trivalent $M^{\prime \text { III }}$. The positive charge acquired by the double-hydroxide layers, $\left[\mathrm{Mg}_{1-x}^{\mathrm{II}} M_{x}^{\prime \text { III }}(\mathrm{OH})_{2}\right]^{x+}$, by this substitution is neutralized by additional anions which reside in the interlayer region along with water molecules, as if they were in a gallery (Fig. 1). This causes an expansion of the structure in the $c$ direction (for example, $c / 3=7.84 \AA$ for HT) as compared to brucite. On the other hand, the $a$ parameter $(3.102 \AA$ for HT) shows little change. The presence of anions in the interlayer region confers unique anion-exchange properties to LDHs (11).

During the course of our investigations of hydroxides of cobalt and nickel (17), we have found that, besides the wellknown $\beta-M(\mathrm{OH})_{2}\left(M=\mathrm{Ni}^{\mathrm{II}}, \mathrm{Co}^{\mathrm{II}}\right)$ which are isostructural with $\mathrm{Mg}(\mathrm{OH})_{2}$, an $\alpha$-hydroxide modification exists for both the metals. While the $\alpha$-modification of nickel(II) hydroxide, which crystallizes in a hexagonal structure has been known for sometime (17b), the corresponding $\alpha$-cobalt(II) hydroxide has been synthesized by us $(17 \mathrm{c})$ recently. Our investigations have led us to believe that the $\alpha$-modifications of nickel(II) and cobalt(II) hydroxides are indeed HT-like possessing a LDH-type structure even in the absence of 


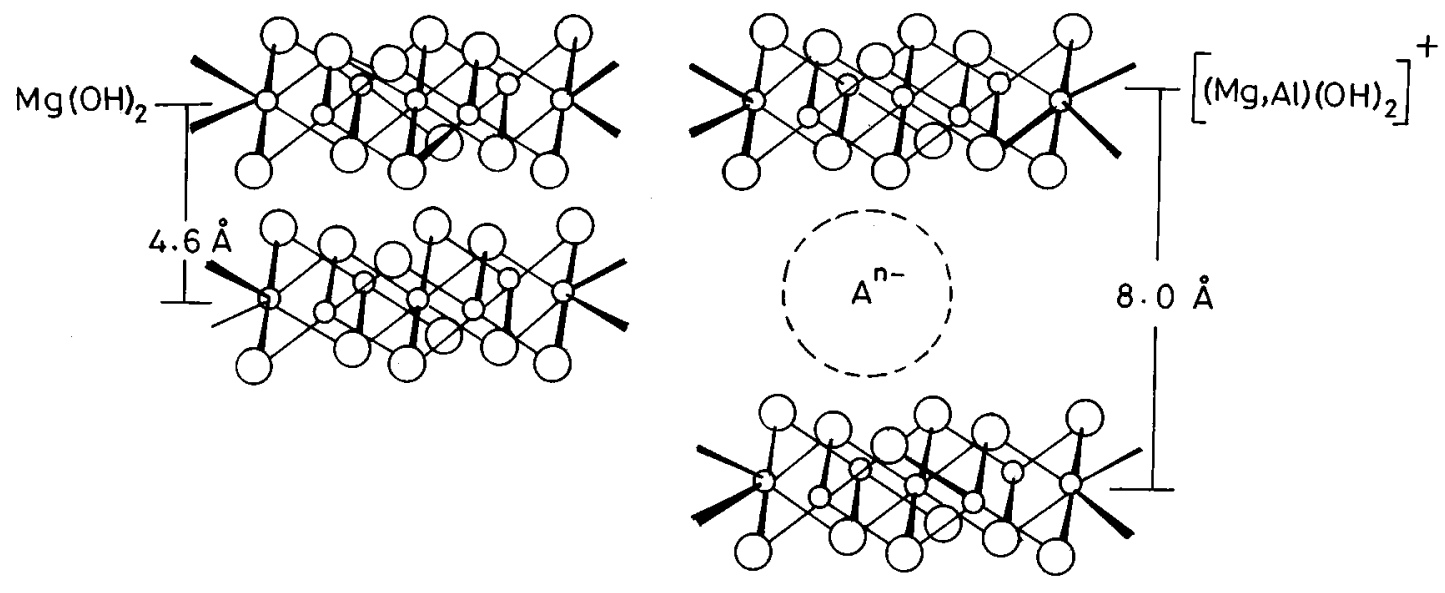

a

b

FIG. 1. A schematic representation of the magnesium hydroxide structure (a) compared with that of the LDH (b). The large open circles are intercalated anions.

trivalent cations. In this paper, we present evidence toward this structural model and suggest that protonation of the hydroxyls is most likely the mechanism that incorporates a positive charge on $M(\mathrm{OH})_{2}$ layers, leading to the formation of a HT-like structure for the $\alpha$-hydroxides.

\section{EXPERIMENTAL}

The $\alpha$-modification of nickel(II) hydroxide was synthesized electrochemically from aqueous solutions of various Ni salts such as nitrate, chloride, or sulfate. Platinum foils of $2 \mathrm{~cm}^{2}$ area were used as electrodes. The hydroxide was deposited at the cathode from a $0.25 \mathrm{M}$ salt solution galvanostatically at a current density of $25 \mathrm{~mA} \mathrm{~cm}^{-2}$ for $10 \mathrm{~h}$ at room temperature $\left(26-28^{\circ} \mathrm{C}\right)$. The product was separated from the electrode, filtered, washed with water, and dried at $100^{\circ} \mathrm{C}$ to constant weight. The $\alpha$-form of cobalt(II) hydroxide was synthesized similarly by cathodic reduction of a $0.1 \mathrm{M}$ cobalt(II) nitrate solution containing $1 \mathrm{wt} \%$ of fructose as additive (17c). The solid products were characterized by powder X-ray diffractometry (XRD) (JEOL JDX-8P powder diffractometer), infrared spectroscopy (Perkin-Elmer 580 Infrared spectrometer, $\mathrm{KBr}$ pellets), and thermogravimetric (TG) analysis. The solid products were also characterized by wet chemical analyses. The metal contents of the hydroxides were estimated gravimetrically using standard methods. The hydroxyl contents were determined by dissolving a known quantity of the solid in excess of $0.4 \mathrm{M} \mathrm{HCl}$, and then back-titrating the excess acid with standard $\mathrm{NaOH}$ using a $\mathrm{pH}$ meter. The chloride and sulfate contents, where applicable, were estimated gravimetrically by precipitation as $\mathrm{AgCl}$ and $\mathrm{BaSO}_{4}$, respectively. The unaccounted weight was attributed to the water content. On the basis of the analytical results, we give the compositions of the $\alpha$-hydroxides of nickel(II) containing nitrate, chloride, and sulfate ions in Table 1 . The total weight losses found from TG analyses are in agreement with the compositions (see Table 1).

TABLE 1

Results of Wet Chemical Analysis of the $\alpha$-Hydroxides of Nickel

\begin{tabular}{|c|c|c|c|c|c|c|}
\hline \multirow{2}{*}{$\begin{array}{l}\mathrm{Ni}(\mathrm{OH})_{2} \\
\text { obtained from }\end{array}$} & \multicolumn{4}{|c|}{ Composition $(\mathrm{wt} \%)^{a}$} & \multirow{2}{*}{$\begin{array}{c}\% \text { Wt. loss }{ }^{b} \\
\text { (TG) }\end{array}$} & \multirow[b]{2}{*}{ Molecular formula } \\
\hline & $\mathrm{Ni}$ & $\mathrm{OH}^{-}$ & $\mathrm{A}^{-}$ & $\mathrm{H}_{2} \mathrm{O}$ & & \\
\hline $\mathrm{Ni}\left(\mathrm{NO}_{3}\right)_{2}$ & 51.2 & 26.9 & 11.2 & 10.7 & $\begin{array}{c}35.6 \\
(34.1)\end{array}$ & $\mathrm{Ni}(\mathrm{OH})_{1.8}\left(\mathrm{NO}_{3}\right)_{0.2}\left(\mathrm{H}_{2} \mathrm{O}\right)_{0.65}$ \\
\hline $\mathrm{NiCl}_{2}$ & 51.5 & 26.2 & 6.8 & 15.5 & $\begin{array}{c}34.0 \\
(34.5)\end{array}$ & $\mathrm{Ni}(\mathrm{OH})_{1.8} \mathrm{Cl}_{0.2}\left(\mathrm{H}_{2} \mathrm{O}\right)_{0.98}$ \\
\hline $\mathrm{NiSO}_{4}$ & 50.9 & 24.5 & 12.4 & 12.3 & $\begin{array}{c}25.4 \\
(25.4)\end{array}$ & $\mathrm{Ni}(\mathrm{OH})_{1.7}\left(\mathrm{SO}_{4}\right)_{0.15}\left(\mathrm{H}_{2} \mathrm{O}\right)_{0.79}$ \\
\hline
\end{tabular}

\footnotetext{
${ }^{a}$ All compositions are reported within an error of $1 \%$.

${ }^{b}$ Values in parentheses correspond to the expected weight loss as calculated from the molecular formula. The product of decomposition is NiO for nitrate and chloride containing hydroxides and $\mathrm{NiO}+\mathrm{NiSO}_{4}$ for the sulfate containing hydroxide.
} 
The absence of trivalent cations in $\alpha$-hydroxides was checked by reactions with excess ferrous ammonium sulfate and back-titrating the excess with standard potassium dichromate. Comparison with a blank titration confirmed the absence of any trivalent ions in the $\alpha$-hydroxides.

\section{RESULTS AND DISCUSSION}

Chemical analysis of the $\alpha$-nickel hydroxides obtained from the nitrate, chloride, and sulfate solutions (Table 1) shows that the compositions can be expressed by the general formula $\left[\mathrm{Ni}(\mathrm{OH})_{2-x}\left(\mathrm{H}_{2} \mathrm{O}\right)_{y}\right]^{x+} A_{x / n}^{n-}$ revealing the presence of a definite amount of anions and water molecules besides the hydroxyl ions. Investigations of $\alpha$-cobalt hydroxides also yielded similar results.

We show in Fig. 2 the powder XRD patterns of $\alpha$-nickel hydroxide and a laboratory synthesized nitrate analog of takovite having the formula $\mathrm{Ni}_{0.75} \mathrm{Al}_{0.25}(\mathrm{OH})_{2}$. $\left(\mathrm{NO}_{3}\right)_{0.25} 0.5 \mathrm{H}_{2} \mathrm{O}$. We also show the XRD patterns of $\alpha$-cobalt hydroxide and the Co-Al LDH $(x=0.25)$. In Table 2 we list the $d$ values for the prominent $h k l$ reflections of the $\alpha$-hydroxides and compare them with those of the $\mathrm{Ni}-\mathrm{Al}$ and $\mathrm{Co}-\mathrm{Al}$ LDHs. It is at once evident that the $\alpha$-hydroxides are isostructural with the LDH phases.

In Fig. 3 we show the infrared spectra of a typical $\alpha$ hydroxide and compare it with that of a LDH. In both spectra, strong vibrations due to intercalated anions (1470, $1380,1310,1050,1000 \mathrm{~cm}^{-1}$ for nitrate) are seen in the $1400-900 \mathrm{~cm}^{-1}$ region. The sulfate containing hydroxides show strong vibrations at 1124 and $1047 \mathrm{~cm}^{-1}$ while the chloride containing hydroxides do not show any absorption in this region as expected. Further, the $\mathrm{OH}$ stretch in the

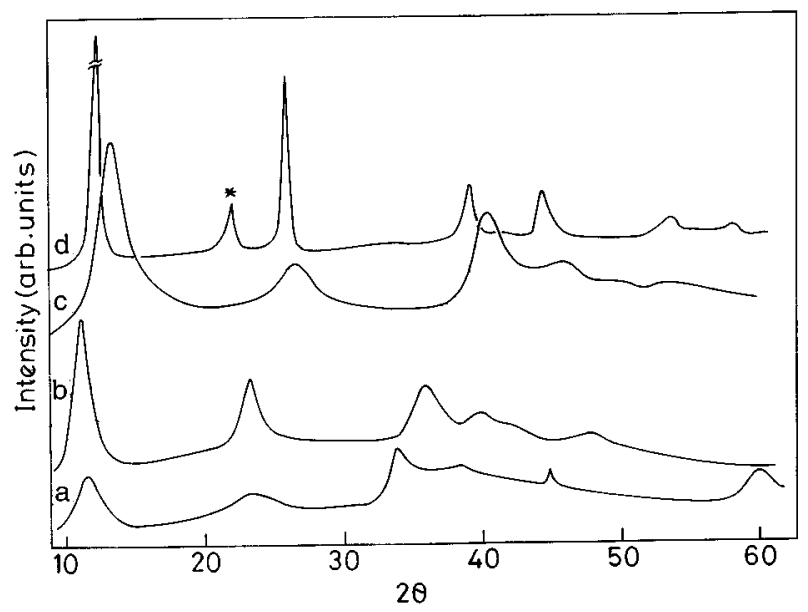

FIG. 2. Power X-ray diffraction patterns of $\alpha$-nickel(II) hydroxide (a), nitrate intercalated synthetic takovite (b), $\alpha$-cobalt(II) hydroxide (c), and $\mathrm{Co}-\mathrm{Al} \mathrm{LDH}$ (d). The patterns at (c) and (d) have been recorded with CoK $\alpha$ $(\lambda=1.790 \AA)$ radiation. The feature marked with an asterisk is an impurity peak due to $\beta$-cobalt hydroxide.
TABLE 2

Comparison of Powder X-ray Diffraction Data of the $\alpha$-Hydroxides of Ni and Co with Their Respective Al Containing LDHs

\begin{tabular}{lcccc}
\hline \multicolumn{5}{c}{$d_{\text {observed }} / \AA$} \\
$h k l$ & $\begin{array}{c}\alpha \text {-Nickel } \\
\text { hydroxide }\end{array}$ & $\begin{array}{c}\mathrm{Ni}-\mathrm{Al} \\
\mathrm{LDH}\end{array}$ & $\begin{array}{c}\alpha \text {-Cobalt } \\
\text { hydroxide }\end{array}$ & $\begin{array}{c}\text { Co-Al } \\
\text { LDH }\end{array}$ \\
\cline { 2 - 5 } 003 & 7.560 & 7.890 & 7.915 & 7.550 \\
006 & 3.780 & 3.895 & 3.890 & 3.820 \\
101 & 2.670 & 2.540 & 2.627 & 2.586 \\
105 & 2.340 & 2.317 & 2.322 & 2.309 \\
107 & 2.030 & 2.222 & 2.112 & 1.938 \\
110 & 1.550 & 1.499 & - & - \\
& $a=3.10 \AA$ & $a=3.09 \AA$ & $a=3.09 \AA$ & $a=3.09 \AA$ \\
& $c 22.68 \AA$ & $c=23.67 \AA$ & $c=23.74 \AA$ & $c=22.65 \AA$ \\
\hline
\end{tabular}

LDHs as well as the $\alpha$-hydroxides appears as a broad band centered around $3450 \mathrm{~cm}^{-1}$, revealing that the hydroxyls are involved in hydrogen bonding with the intercalated water molecules. These spectral features of the $\alpha$-hydroxides are consistent with the chemical compositions given in Table 1. On the other hand brucite-like $\beta$ hydroxides show a strong sharp $\mathrm{OH}$ stretch around $3650 \mathrm{~cm}^{-1}$ which indicates the presence of nonhydrogen bonded $\mathrm{OH}$ groups (18).

These results show that, in terms of both long range and short range structure, the $\alpha$-hydroxides of nickel and cobalt are HT-like phases, containing a definite amount of intercalated anions, even though there are no trivalent cations. While the relationship between the LDH and $\alpha$-hydroxides has already been demonstrated in the literature $(13,19)$, the exact mechanism of incorporation of positive charge on the $M(\mathrm{OH})_{2}$ layers of the $\alpha$-hydroxides has not been established. However, there has been considerable speculation in the literature on the mechanism of incorporation of anions in $\alpha$-hydroxides of this type. We briefly discuss the various models in the light of the literature data and experimental evidence.

(a) Kamath and Vasanthacharya (17a) attributed the presence of anions in $\alpha$-nickel hydroxide to the possible existence of nickel in a mixed (II and III) valent state. If this were true, it would make the $\alpha$-hydroxide exactly identical

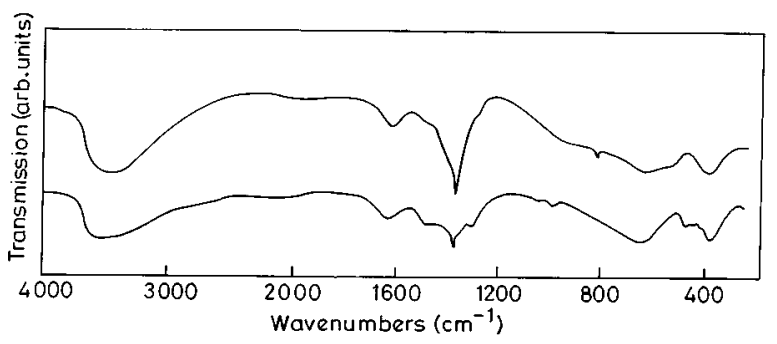

FIG. 3. Infrared spectra of $\alpha$-nickel(II) hydroxide (lower curve) compared with that of nitrate intercalated synthetic takovite (upper curve). 
to LDHs, except that the same metal exists in the (II) and (III) states in the $\alpha$-hydroxide.

(b) Faure et al. (19) and Delahaye-Vidal et al. (20) suggested the presence of hydroxyl vacancies in the $\alpha$-hydroxide layers, leading to the incorporation of anions in the interlayer space for charge balance.

(c) Bish and Livingstone (21) proposed inclusion of cation-anion pairs in the interlayer region. Such cation-anion pairs have indeed been found in the mineral hydrohonessite.

(d) A fourth possibility is the direct coordination of the anions to the metal, as in hydroxysalts (22) such as $\mathrm{Ni}_{3}(\mathrm{OH})_{4}\left(\mathrm{NO}_{3}\right)_{2}$.

(e) A fifth possibility involves incorporation of additional $M$ (II) cations at interstitial (tetrahedral) sites of the $\alpha$-hydroxide layers (23). This possibility is realized in the layered hydroxy-nitrate, $\mathrm{Zn}_{5}(\mathrm{OH})_{8}\left(\mathrm{NO}_{3}\right)_{2} \cdot 2 \mathrm{H}_{2} \mathrm{O}$, where onefourth of the $\mathrm{Zn}(\mathrm{II})$ at octahedral sites is replaced by pairs of tetrahedrally coordinated $\mathrm{Zn}(\mathrm{II})$ on each side of the hydroxide layer giving the layer composition, $\left[\mathrm{Zn}_{5}(\mathrm{OH})_{8}\right]^{2+}$. This compound crystallizes in a monoclinic structure $(a=$ $19.48 \AA, b=6.238 \AA, c=5.517 \AA$, and $\beta=93.28$ ) and is not isostructural with either the LDHs or the $\alpha$-hydroxides despite having a composition similar to the latter, $\mathrm{Zn}(\mathrm{OH})_{2-x}\left(\mathrm{NO}_{3}\right)_{x} \cdot m \mathrm{H}_{2} \mathrm{O}(x=0.4 ; m=0.4)$.

All the above models for $\alpha$-hydroxides can be discounted on the basis of experimental data except probably model (b). Model (a) is inappropriate because there is no detectable $\mathrm{Ni}(\mathrm{III}) / \mathrm{Co}$ (III) in the $\alpha$-hydroxides; the hydroxides are green/green-blue in color. Model (b), suggesting that hydroxyl vacancies in $M(\mathrm{OH})_{2}$ layers are occupied by anions, does not bring out the actual mechanism of incorporation of positive charge on the hydroxide layers. Model (c) could be ruled out because inclusion of cation-anion pairs would result in much larger interlayer spacings $(\sim 11 \AA)$. Such large interlayer spacings are not seen for the $\alpha$-hydroxides. Model (d) also could be ruled out considering that this model should lead to much smaller interlayer spacing $(\sim 6.9 \AA)$ than what is observed for the $\alpha$-hydroxides. Model (e) is obviously inappropriate for the $\alpha$-hydroxides because nickel(II) normally does not occupy tetrahedral sites in oxides/hydroxides. Even cobalt(II) does not go to tetrahedral sites when the synthesis is carried out in aqueous media. Moreover, a tetrahedral cobalt(II) would have imparted a distinct blue color to the sample and led to a monoclinic structure as in the case of zinc hydroxynitrate.

A most likely model for the $\alpha$-hydroxides, which would account for the inclusion of anions as well as water molecules in the interlayer space, would be partial protonation of the hydroxyls giving rise to a net positive charge on the $\alpha$-hydroxide layers,

$$
M(\mathrm{OH})_{2}+x \mathrm{H}^{+} \Leftrightarrow\left[M(\mathrm{OH})_{2-x} \cdot\left(\mathrm{H}_{2} \mathrm{O}\right)_{x}\right]^{x+} .
$$

The extent of protonation and hence the magnitude of the positive charge on the hydroxide layers would depend on the hydrolysis behavior of $M(\mathrm{II})$ ions in aqueous media (24). This model would also account for the surprisingly high proton diffusion coefficient of $\alpha$-nickel(II) hydroxide (25) which enables the $\alpha$-hydroxides to function as electrode materials in alkaline secondary batteries.

\section{SUMMARY}

In conclusion, we suggest that a partial protonation of the hydroxyls of the $M(\mathrm{OH})_{2}$ layers is the most likely mechanism for the incorporation of positive charge on the layers that gives rise to anion and water intercalated $\alpha$-hydroxides of these metals.

\section{ACKNOWLEDGMENT}

Two of us (PVK and GHAT) thank the Department of Science and Technology, Government of India for financial support.

\section{REFERENCES}

1. R. Allman, Acta Cryst. B 24, 972 (1968).

2. S. A. DeWaal and E. A. Viljoen, Am. Miner. 56, 1077 (1971).

3. D. L. Bish and G. W. Brindley, Am. Miner. 62, 458 (1977).

4. D. L. Bish and A. Livingstone, Miner. Mag. 44, 339 (1981).

5. P. J. Dunn and D. R. Peacor, Am. Miner. 64, 127 (1979).

6. G. W. Brindley, Miner. Mag. 43, 337 (1979).

7. R. S. W. Braithwait, P. J. Dunn, R. G. Pritchard, and W. Parr, Miner. Mag. 58, 79 (1994).

8. K. A. Carrado, A. Kostapapas, and S. Suib, Solid State Ionics 26, 77 (1988).

9. (a) H. P. Boehm, J. Steinle, and C. Vieweger, Angew. Chem. Int. Ed. Engl. 16, 265 (1977); (b) H. F. W. Taylor, Miner. Mag. 39, 304 (1973).

10. V. R. Constantino and T. J. Pinnavaia, Inorg. Chem. 34, 883 (1995).

11. A. Ookuba, K. Ooi, and H. Hayashi, Langmuir 9, 1418 (1993).

12. E. Uzunova, D. Klissurski, I. Mitov, and P. Stefanov, Chem. Mater. 5, 576 (1993).

13. P. V. Kamath, M. Dixit, L. Indira, A. K. Shukla, V. G. Kumar, and N. Munichandraiah, J. Electrochem. Soc. 141, 2956 (1994).

14. H. C. B. Hansen, C. B. Koch, and R. M. Taylor, J. Solid State Chem. 113, 46 (1994).

15. W. T. Reichle, Solid State Ionics 22, 135 (1986).

16. L. Indira and P. V. Kamath, J. Mater. Chem. 4, 1487 (1994).

17. (a) P. V. Kamath and N. Y. Vasanthacharya, J. Appl. Electrochem. 22, 483 (1992); (b) P. V. Kamath, J. Ismail, M. F. Ahmed, G. N. Subbanna, and J. Gopalakrishnan, J. Mater. Chem. 3(12), 1285 (1994); (c) J. Ismail, M. F. Ahmed, P. V. Kamath, G. N. Subbanna, S. Uma, and J. Gopalakrishnan, J. Solid State Chem. 114, 550 (1995).

18. P. V. Kamath and S. Ganguly, Mater. Lett. 10, 537 (1991).

19. C. Faure, C. Delmas, and M. Fouassier, J. Power Sources 35, 279 (1991).

20. A. Delahaye-Vidal, K. Tekaia Ehlsissen, P. Genin, and M. Figlarz, Eur. J. Solid State Inorg. Chem. 31, 823 (1994)

21. D. L. Bish and A. Livingstone, Miner. Mag. 44, 339 (1981).

22. (a) P. Gallezot and M. Prettre, Bull. Soc. Chim. (France) 2, 407 (1969); (b) P. Rabu, S. Angelov, P. Legoll, M. Belaiche, and M. J. Drillon, Inorg. Chem. 32, 2463 (1993).

23. P. Benard, J. P. Auffredic, and D. Louer, Thermochem. Acta 232, 65 (1994).

24. C. F. Baes Jr. and R. E. Mesmer, "Hydrolysis of Cations," pp. 238-247. Kreiger, FL, 1986.

25. D. M. MacArthur, J. Electrochem. Soc. 117, 729 (1970). 